\title{
FEASIBILTY OF ZEIN PROTEINS, SIMPLE SEQUENCE REPEATS AND PHENOTYPIC TRAITS FOR BACKGROUND SELECTION IN QUALITY PROTEIN MAIZE BREEDING
}

\author{
M. MAPHOSA, G. OBALLIM, A. NALUKENGE, R. EDEMA and P. OKORI \\ Department of Crop Science, Makerere University, P. O. Box 7062, Kampala, Uganda \\ Corresponding author: pokori@ agric.mak.ac.ug
}

Recieved 9 September, 2010; accepted 28 April, 2011)

\begin{abstract}
Widespread adoption of quality protein maize (QPM), especially among tropical farming systems has been slow mainly due to the slow process of generating varieties with acceptable kernel quality and adaptability to different agroecological contexts. A molecular based foreground selection system for opaque 2 (o2), the cause of enhanced lysine content in maize exists. Background selection systems albeit, are poorly developed in spite of the mapping of putative loci associated with kernel modification and knowledge on causes of modification. The aim of this study was to develop background selection systems for $\mathrm{o} 2$ introgression into locally adapted genotypes. Experiments were conducted at Makerere University Agricultural Research Institute, Kabanyolo (MUARIK), in Uganda on backcross progeny (BC1F1) and BC2F2), derived from a locally adapted line 136R and a QPM donor CML176. We tested the use of zein proteins known to influence modification as well as DNA markers and phenotypic descriptors as tools for background selection for recurrent parent genome and modifier loci in locally adapted maize genotypes. Simply inherited traits such as maize streak virus disease resistance were suitable for background selection. Other traits include plant and ear heights. The simple sequence repeats markers mapped to chromosomes $3,5,7$, respectively and associated with quantitative trait loci (QTL) conditioning resistance in maize to grey leaf spot and anthesis to silking interval were suitable for assay of recurrent parent genome. The $27-\mathrm{kDa} \gamma$ zein protein levels was suitable for background selection for kernel modification. It should, however, be used along with other zeins such as the $22 \mathrm{kDa}$ and $19 \mathrm{kDa}$ zein proteins.
\end{abstract}

Key Words: Opaque 2 (o2), QPM, SSR, Zea mays

\section{RÉSUMÉ}

L'adoption du maïs de proténe de qualité (QPM), spécialement parmi les systèmes culturaux tropicaux a été lente principalement due au processus lent de génération de variétés avec de grains acceptables de qualité et d'adaptabilité à différents contextes agroécologiques. Il existe une cause du contenu amélioré de la lysine dans le maïs, un système basé sur la sélection moléculaire opaque 2 (o2). Malgré les systèmes de sélection de fond, ceux-ci sont pauvrement développés en dépit du "mapping" du loci associé avec la modification du grain et la connaissance sur les causes de modification. L'objet de cette étude était de développer les systèmes de sélection de fond pour l'introgression o2 dans les génotypes localement adaptés. Des essais étaient conduits sur la progénie de "backcross" (BC1F1) et BC2F2), dérivés de lignées adaptées 136R et un QPM doneur CML176. Nous avons testé l'usage des protéines zéines capables d'influencer de modifications des marqueurs d'ADN et descripteurs phénotypiques comme matériel de sélection de fond pour parent de génome recurrent et modifiant de loci dans les génotypes de ma ¿s localement adaptés. Des traits simplement hérités dont la résistance à la maladie de virus de mèche étaient appropriés pour la sélection de fond. D'autres traits incluaient la hauteur de plants et la taille de l'épis. Les marqueurs SSR représentés sur les chromosomes 3,5,7, respectivement et associés aux traits quantitatifs loci (QTL) conditionnant la résistance dans le mąs à la maladie de tâche grise de feuilles ansi que l'intervalle de 
l'anthesis jusqu'à la sécrétion du "silk" étaient appropriés pour évaluation du génome parent recurrent. Les niveaux

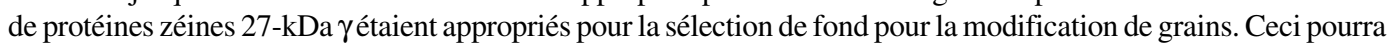
être utilisé à côté d'autres zéines telles que les protéines zéines 22 kDa et 19 kDa.

Mots Clés: Opaque 2 (o2), QPM, SSR, Zea mays

\section{INTRODUCTION}

Maize (Zea mays L.) is an important part of human, livestock and poultry diets in many subSaharan countries and the worldover (CIMMYT, 2005; Gupta et al., 2009). The significant role of maize in especially human nutrition is compounded by the low levels of essential amino acids such as lysine and tryptophan (Hoisington, 2002; Gibbon and Larkins, 2005; Krivanek et al., 2007; Denic et al., 2008). Both lysine and tryptophan are deficient in maize meal because of the abundance of zein storage proteins that lack these amino acids (Gibbon and Larkins, 2005; Wu et al., 2010).

The 1960's discovery of a natural mutation called opaque 2 (o2), causes reduction of zeins, the most abundant seed protein and increases non-zein proteins in the grain. As a consequence, doubles lysine levels needed for improvement of maize protein quality (Mertz et al., 1964; Krivanek et al., 2007; Wu et al., 2010). Unfortunately, the o2 mutation has negative pleiotropic effects that result in soft, chalky and dull endosperm, as well as susceptibility to cob rots and grain pests (Babu et al., 2005). The negative effects of o2 can, however, be overcome by certain loci called "modifiers" capable of ameliorating the negative effects of the mutation (Gibbon and Larkins, 2005; Wu et al., 2010). The process produces a modified kernel called quality protein maize (QPM) comparable in quality to normal maize, but with elevated levels of lysine and tryptophan (Coleman et al., 1997; Hunter et al., 2002).

Widespread adoption of QPM, especially for tropical germplasm and farming systems has been low, due to the slow process of breeding improved varieties with acceptable quality and adaptable to production ecological contexts (Moose et al., 2004; Babu et al., 2005). Moreover, there are several additional biotic and abiotic stresses that compound successful adoption of QPMs in Uganda and many tropical countries. These stresses include Turcicum Leaf Blight (Exserohilum turcicum Pass Teliomorph Setosphaeria turcica, Leonard, K.J. and Suggs, E.G.) maize streak gemini virus disease, grey leaf spot (Cercospora zeae maydis Tehon and Daniels), and drought (Okori et al., 1999; Pixley, 2001; Ngaboyisonga et al., 2006; Pratt and Gordon, 2006).

Successful development of QPM requires introgression of 02 while selecting for suitable genetic modifier background to guarantee the development of high quality vitreous kernels. Genetic analysis of o2 modifiers has led to the identification of loci that affect packaging of starch granules in grain (Lopes et al., 1995; Gibbon et al., 2003) and alternation of zein proteins critical for modification (Geetha et al., 1991; Lopes and Larkings 1991). Although their molecular identities have remained unknown, these modifier loci are correlated with increases in 27-kDa $\gamma$-zein transcript and protein in QPM (Geether et al., 1991).

Unlike the 22-kDa $\alpha$-zein genes, the 27-kDa $\gamma$-zein gene is not under the transcriptional control of the O2 protein (Schmidt, 1993). Two different QTLs, which are candidates for o2 modifier genes, affect 27-kDa $\gamma$-zein gene expression (Wang et al., 2001). Recently, it has been shown that $\alpha$ zeins restore protein body density and starch grain interaction, activities necessary for modification in QPM (Wu et al., 2010). Thus, the previous studies on opaque two and its regulation in modified maize highlight opportunity to develop systems for selection of o2 modifier background.

Selection of o2 during line conversion is usually done through backcross breeding schemes based on known genetic markers such as the simple sequence repeats (SSRs) phi057, phi112 and a non-SSR genetic marker umc1066 (Babu et al., 2005; Okello et al., 2006; Manna et al., 2006). This process, also referred to as foreground selection, ensures that target loci are introgressed in the appropriate genetic 
background. Selection of modifier background and recurrent parent genome, however, remain a challenge (Frisch et al., 1999). Kernel modification is influenced by a complex of genes that act in an additive and non-additive manner, and this in part accounts for the varied levels of kernel modification observed in QPM. It is, therefore, of interest to test the use of the $\gamma, \alpha$ and $\beta$ zein proteins that influence kernel modification as tools for modifier background selection. Such a study would contribute to knowledge on the use of proteins as tools for marker assisted breeding as well as the use of such loci for QPM breeding. Moreover, some of the modifier loci have been mapped to chromosomes 1 and 4 of maize (Wang et al., 2001; Gibbon and Larkins, 2005).

The aim of this study was to test the use of zein proteins, SSRs and phenotypic traits as tools for background selection of recurrent parent genome and suitable modifier loci in locally adapted maize genotypes.

\section{MATERIALS AND METHODS}

Plant material and layout of the experiment. Maize inbred lines CML 176 and 136R, together with already developed backcross populations (BC1F2 and BC2F2) (Okello et al., 2006) were used in the study. CML 176 is a QPM donor line from the International Maize and Wheat Improvement Center (CIMMYT) (Okello et al., 2006). Maize line 136R is a recycled inbred from the National Cereals Programme at National Crops Resources Research Institute (NaCRRI) in Uganda, resistant to maize streak gemini virus disease (MSVD), grey leaf spot (GLS), turcicum leaf blight (TLB) and drought. These traits are important in various maize growing regions. Due to its adaptation to the local conditions, it was targeted for conversion to QPM.

The experiment was conducted at NaCRRI. The plots consisted of inbreds and backcross progeny replicated four times following a randomised complete block design. Each plot consisted of 20 individuals planted at $75 \mathrm{~cm} \mathrm{x}$ $25 \mathrm{~cm}$ spacing.
Characterisation of phenotypic descriptors for background selection. Phenotypic descriptors, namely, incidence and severity of GLS, TLB and MSVD were monitored at flowering under natural infestation. For MSVD, a qualitative scale of 1-5 was used to assess disease severity, where $1=$ resistant and $5=$ susceptible based on the chlorotic/streaked areas on the leaf surface (Kyetere et al., 1999; Muriithi and Mutinda, 2001). Other descriptors recorded included plant height, 1000 grain weight (at 12\% moisture content), ear height, days to silking and days to pollen shed. These are important phenotypic traits that normally form the basis for background selection in conventional breeding programmes, and are characteristic of genotypes (Babu et al., 2004a).

\section{Molecular analysis for background selection} markers. The possible role and use of seed proteins and the genome as genetic tools for background selection was investigated. This approach was used to expand the analytical scope for identification of putative genetic markers, given that the genome and the zeins (the most abundant seed proteins), especially the 27 $\mathrm{kDa} \gamma$ fraction has been implicated in the modification of kernels (Lopes and Larkins, 1991). Other zein and non-zein proteins have also been implicated, especially starch synthases. The methods used for both genomic and proteome analyses are presented below.

Genomic analysis. Leaf tissue for each line was harvested from healthy looking and young three- to four-week old seedlings. Genomic DNA was isolated using a modified hot cetyltrimethyl-ammonium bromide (CTAB) DNA extraction procedure (Hoisington et al., 1994). Molecular background marker analysis was conducted using 24 SSR that targeted regions of chromosomes $1,3,5,7,8$ and 9 of the maize genome. These chromosomes represent the parts of the genome that regulate the most important agronomic traits. Chromosome 1 has loci that controls MSVD resistance; Chromosomes 3 and 5 have loci that controls GLS resistance; Chromosome 7 has 
loci that controls anthesis-to-silking interval; Chromosome 8 has loci that controls TLB resistance and chromosome 9 has loci that controls grain number (Lehmensiek et al., 2001; Pratt., 2004; Xiao et al., 2005).

The SSRs were chosen based on bin locations linked to important agronomic trait loci. Primer sequences and bin locations for the selected SSRs are shown in Table 1. The sequences of the 24 primer pairs used to amplify the maize SSRs were obtained from CIMMYT and synthesised by Molecular and Cell Biology Laboratory (University of Cape Town, South Africa). Approximate sizes of the PCR amplicons were determined using a 100 base pair molecular weight ladder (Promega, Madison, USA). Initial screening for polymorphism between the two parental inbreds was based on the 24 informative SSR loci. Subsequently, the loci found to be polymorphic were used to screen the backcross progeny.

The reactions were carried out in PCR thermocyclers; iCycler (Bio-Rad, California, USA) and GeneAmp 9700 (Applied Biosystems, California, USA). The process consisted of an initial denaturing phase at $94{ }^{\circ} \mathrm{C}$ for 2 minutes, followed by 33 cycles of amplification at $94{ }^{\circ} \mathrm{C}$ for 2 minutes, $55-60{ }^{\circ} \mathrm{C}$ (depending on the sequence) for 1 minute 30 seconds, and $72{ }^{\circ} \mathrm{C}$ for 1 minute 30 seconds. A final extension step at $72{ }^{\circ} \mathrm{C}$ for 10 minutes was followed by termination of the cycle at $4{ }^{\circ} \mathrm{C}$. The $20 \mu \mathrm{l} \mathrm{PCR}$ reaction mix consisted of $1 \mathrm{X}$ reaction buffer (Promega, Madison, USA), $2.5 \mathrm{mM} \mathrm{MgCl}, 0.4$ $\mathrm{mM}$ of dNTPs, $0.25 \mu \mathrm{M}$ ?of each primer, 1 unit of Taq DNA polymerase (Promega, Madison,

TABLE 1. Primer sequences, SSRs and the respective bin locations of loci investigated for use as genetic molecular markers for background selection in QPM maize breeding

\begin{tabular}{|c|c|c|c|}
\hline Locus & Bin number & Repeat type & Sequence \\
\hline phi002 & 1.08 & $\mathrm{AACg}$ & CATgCAATCAATAACgATggCgAgT // TTAgCgTAACССTTCTCCAgTCAgC \\
\hline phi011 & 1.09 & $\mathrm{AgC}$ & TgTTgCTCggTCACCATACC // gCACACACACAggACgACAgT \\
\hline phi056 & 1.01 & $\mathrm{CCg}$ & ACTTgCTTgCCTgCCgTTAC // CgCACACCACTTCCCAgAA \\
\hline umc1122 & 1.06 & $(\mathrm{CgT}) 7$ & CACAACTCCATCAgAggACAgAgA// CTgCTACgACATACgCAAggC \\
\hline phi046 & 3.08 & $\mathrm{ACgC}$ & ATCTCgCgAACgTgTgCAgATTCT // TCgATCTTTCCCggAACTCTgAC \\
\hline phi053 & 3.05 & ATAC & CTgCCTCTCAgATTCAgAgATTgAC // AACCCAACgTACTCCggCAg \\
\hline phi374118 & 3.02 & ACC & TACCCggACATggTTgAgC // TgAAgggTgTCCTTCCgAT \\
\hline phi102228 & 3.06 & AAgC & ATTCCgACgCAATCAACA // TTCATCTCCTCCAggAgCCTT \\
\hline phi087 & 5.06 & ACC & gAgAggAggTgTTgTTTgACACAC //ACAACCggCAAgTCAgCAgATTg \\
\hline phi109188 & 5.03 & AAAg & AAgCTCAgAAgCCggAgC // ggTCATCAAgCTCTCTgATCg \\
\hline nc130 & 5.00 & $\mathrm{AgC}$ & gCACATgAAgATCCTgCTgA // TgTggATgACggTgATgC \\
\hline phi331888 & 5.04 & AAg & TTgCgCAAgTTTgTAgCTg // ACTgAACCgCATgCCAAC \\
\hline phi034 & 7.02 & CCT & TAgCgACAggATggCCTCTTCT // ggggAgCACgCCTTCgTTCT \\
\hline phi1545 & 7.00 & $(\mathrm{AAgA}) 4$ & gAAAACTgCATCAACAACAAgCTg // ATTggTTggTTCTTgCTTCCATTA \\
\hline phi114 & 7.03 & gCCT & CCgAgACCgTCAAgACCATCAA // AgCTCCAAACgATTCTgAACTCgC \\
\hline phi328175 & 7.04 & Agg & gggAAgTgCTCCTTgCAg // CggTAggTgAACgCggTA \\
\hline phi014 & 8.04 & ggC & AgATgACCAgggCCgTCAACgAC // CCAgCTTCACCAgCTTgCTCTTCgTg \\
\hline phi233376 & 8.09 & $\mathrm{CCg}$ & CCggCAgTCgATTACTCC // CgAgACCAAgAgAACCCTCA \\
\hline umc1304 & 8.02 & $\mathrm{TCgA}) 4$ & 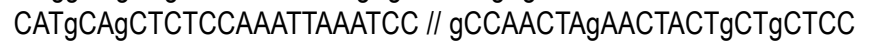 \\
\hline umc1161 & 8.06 & (gCTggg) 5 & gTACCgCTACTgCTTgTTACTgC // gCTCgCTgTTggTAgCAAgTTTTA \\
\hline umc1279 & 9.00 & $(\mathrm{CCT}) 6$ & gATgAgCTTgACgACgCCTg // CAATCCAATCCgTTgCAggTC \\
\hline umc1277 & $9.07-9.08$ & (AATA)5 & TTTgAgAACggAÄCAAgTACTCC // ACCAACCAACCACTCCCTTTTTAg \\
\hline phi032 & 9.04 & AAAg & CTCCAgCAAgTgATgCgTgAC // gACACCCggATCAATgATggAAC \\
\hline phi448880 & $9.06-9.07$ & AAg & CgATCCggAggAgTTCCTTA // CCATgAACATgCCAATgC \\
\hline
\end{tabular}

Loci on chromosome 1 condition resistance to maize streak virus disease, chromosome 3 and 5 condition resistance to grey leaf spot, chromosome 7 regulates anthesis to silking intervals, chromosome 8 conditions resistance to turcium leaf blight whilst chromosome 9 conditions grain number per cob 
USA), water and $50 \mathrm{ng}$ of DNA. Reactions were stopped using $10 \mu$ l loading dye $[0.25 \%$ bromophenol dye, $0.25 \%$ xylene cyanol FF, $30 \%$ glycerol, formamide]. A total of $3.5 \mu \mathrm{l}$ of the mix was loaded into the wells of a $6 \%$ vertical denaturing PAGE system (OWL T-Rex) (ThermoFisher Scientific, Portmouth, USA). A running buffer, $1 \mathrm{X}$ TBE $(0.83 \mathrm{M}$ Boric acid, Tris$\mathrm{HCl} 1 \mathrm{M}$, EDTA $10 \mathrm{mM}$ ), was used. Electrophoresis was performed at $1800 \mathrm{~V}, 50 \mathrm{~mA}, 150$ W for 2-3 hours. The separated bands were visualised using silver nitrate (Strategene, 1998). All solutions were prepared using deionised distilled water from EASYpure RF water purification system (Barnstead, Iowa, USA).

Statistical analyses. All phenotypic data were subjected to analysis of variance (ANOVA) using GenStat Release 7.1 (2003) (Lawes Agricultural Trust, Rothamsted, UK). Where significant differences were found, means were compared using Fischer's Protected least significance difference test (LSD) at $\mathrm{P}<0.05$ (Steel et al., 1997). For the SSR, data a Chi-square test for goodness of fit test with a Yates correction term was done to determine deviation from the $136 \mathrm{R}$ recurrent parent.

\section{Proteome based analysis}

Grain selection. Maize kernels with varying levels of modification was used. Kernel modification was assessed on a $1=5$ scale, where $1=$ modified (vitreous), 2=75\% modified, $3=$ $50 \%$ modified, $4=25 \%$ modified and $5=100 \%$ opaque (non-modified) (Bantte and Prasanna, 2004) (Fig. 1). Modification scores were derived based on the evaluation of 100 randomly selected kernels from the ears of the each backcross genotypes obtained through controlled pollination.
Protein extraction and visualisation. Zein proteins were extracted as described by Schmidt (1993). Proteins were prepared for electrophoresis by boiling a mixture of $30 \mu \mathrm{l}$ ethanol extract, $70 \mu \mathrm{l}$ deionised water and $50 \mu \mathrm{l}$ $3 \mathrm{X}$ extraction buffer $(0.2 \mathrm{M}$ Tris- $\mathrm{HCl}, 4.5 \%$ SDS, $12 \%$ b-mercaptoethanol, $30 \%$ glycerol and $0.06 \%$ bromophenol blue). Protein samples (15 $\mu \mathrm{l})$ were loaded into a Criterion XT pre-cast BisTris, $12 \%$ gel and run at $180 \mathrm{~V}$ for 1 hour in a vertical protein cell (CRITERION ${ }^{\mathrm{TM}}$ ). Precision Plus Dual Class Standards ${ }^{\mathrm{TM}} 250 \mathrm{kD}$ were used to estimate the sizes of the different zein proteins. MOPS $1 \mathrm{X}$ solution was used as a running buffer. Gels were stained in $200 \mathrm{ml}$ of Coomassie Blue Stain 1X solution overnight on a shaker at 20 RPM. De-staining was done with a de-stain Coomassie R-250 1X solution, until the desired band intensity, i.e. when all bands were clearly visible and distinguishable from background was attained. The destained gels were scanned in a Calibrated Imaging Densitometer GS- $800^{\mathrm{TM}}$ using the programme MagicScan32 V4.5 (UMAX Data Systems, Santa Barbara, USA) (1996). All the reagents (extraction, electrophoresis and staining and de-staining) and equipment used for the protein assay were supplied by Bio-Rad, California, USA.

\section{RESULTS}

\section{Putative molecular markers for background selection of critical phenotypic traits}

Simple sequence repeats (SSRs). Out of the 24 SSRs screened from the two parents, 14 $(58 \%)$ were polymorphic (Fig. 2). There was wide variation in the number and size of alleles amplified, with some chromosome regions failing to amplify, while others had as many as 10 alleles (Table 2). Loci that amplified different numbers of alleles were considered

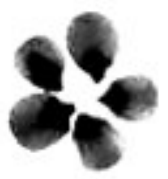

1

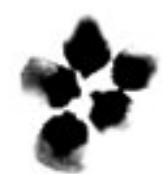

2

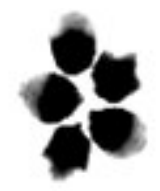

3

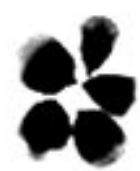

4

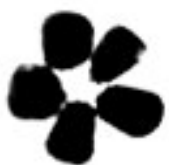

5

Figure 1. Kernel standards (white light backlit) used for analysing zein proteins. 

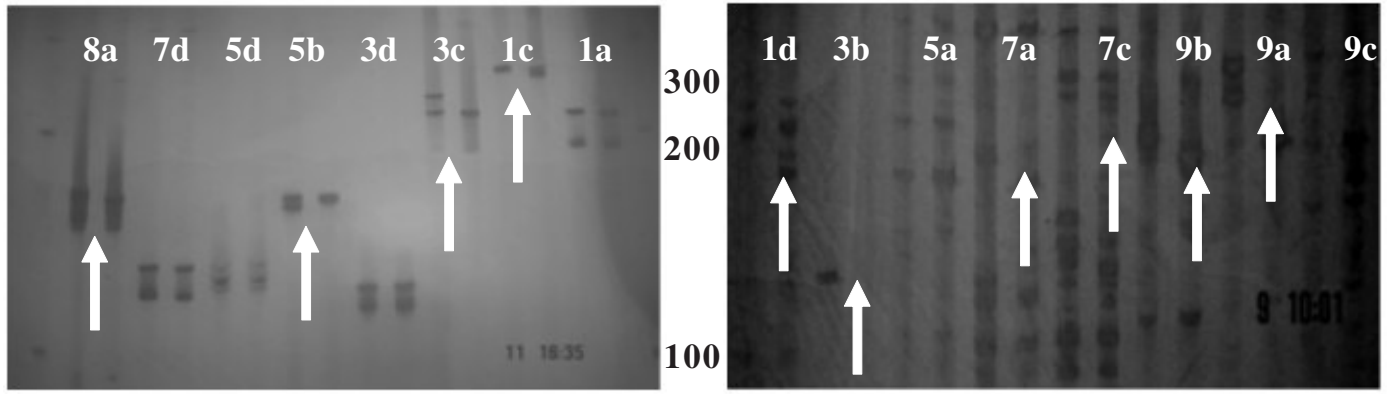

(a)

(b)

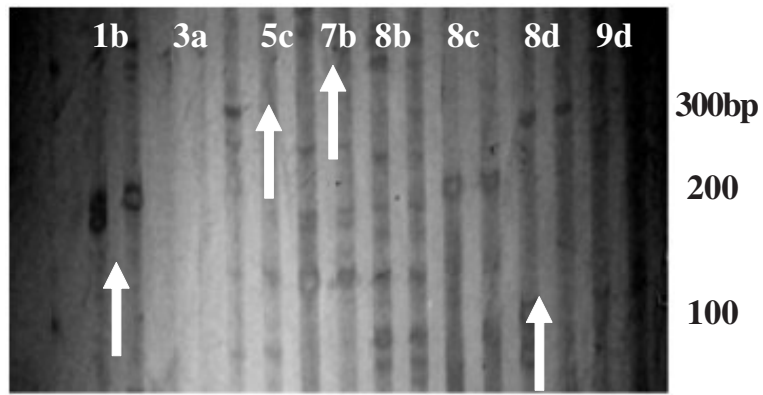

(c)

Figure 2. SSR markers on polyacrylamide gel visualised by silver staining. Panels $a, b$ and $c$ are results for different SSR screens across different maize loci. The SSRs were tagged to different chromosomes loci indicated by numbers in the top panel. Different alleles at the same loci are represented by letters following the chromosome number (e.g. $5 \mathrm{~d})$. The arrows indicate polymorphism between parents. Each chromosome region was represented in both parents (136R and CML 176).

1b 1c 1d 3b 3c 5b 5c 7a 7b 7c 8a 8d 9a 9b

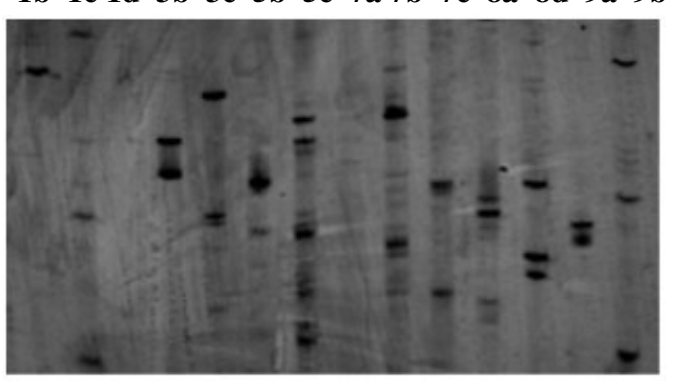

1b 1c 1d 3b 3c 5b 5c 7a 7b 7c 8a 8d 9a 9b

Figure 3. SSR markers of BC1F2 (a) and BC2F2 (b) progeny on polyacrylamide gel visualised by silver staining. The SSRs are tagged to different chromosomes loci numbered in the top of the panel. Different alleles at the same loci are represented by letters following the chromosome number (e.g. 5 d).

polymorphic. Subsequent screens of backcross progeny using the polymorphic SSRs, consistently confirmed their presence in the advanced populations (Fig. 3). Out of 14 polymorphic SSRs between the recurrent and non-recurrent parents, only 4 SSR loci were consistently identified in the $\mathrm{BC}_{1} \mathrm{~F}_{2}$ and two in the $\mathrm{BC}_{2} \mathrm{~F}_{2}$ generation (Table 2). These SSR loci mapped to chomosomes 3,5, and 7, respectively. The Chi-square goodness of fit test showed that these loci on selected chromosomes were consistent with the recurrent parent $\left(\mathrm{c}^{2}<\mathrm{c}^{2}{ }_{0.05}=\right.$ 
TABLE 2. Summary of the polymorphism screen between the parental inbreds CML176 and 136R

\begin{tabular}{|c|c|c|c|c|c|c|c|}
\hline \multirow[t]{2}{*}{$\begin{array}{l}\text { Chromosome } \\
\text { and their loci }\end{array}$} & \multirow[t]{2}{*}{ Locus } & \multicolumn{2}{|c|}{ Number of alleles } & \multirow[t]{2}{*}{ Trait } & \multirow[t]{2}{*}{$\begin{array}{l}\text { Polymorphism } \\
\text { detected }\end{array}$} & \multicolumn{2}{|c|}{$\begin{array}{l}\text { Recovery in } \\
\text { backcross progeny }\end{array}$} \\
\hline & & CML176 & $136 \mathrm{R}$ & & & $\mathrm{BC} 1 \mathrm{~F} 2$ & $\mathrm{BC} 2 \mathrm{~F} 2$ \\
\hline $1 a$ & phi002 & 2 & 2 & MSV & No & No & No \\
\hline $1 b$ & phi011 & 3 & 4 & MSV & Yes & No & No \\
\hline $1 \mathrm{c}$ & phi056 & 1 & 3 & MSV & Yes & No & Yes \\
\hline $1 d$ & umc1122 & 4 & 6 & MSV & Yes & Yes & No \\
\hline $3 a$ & phi046 & 1 & 1 & GLS & No & No & No \\
\hline $3 b$ & phi053 & 1 & 0 & GLS & Yes & Yes & Yes \\
\hline $3 c$ & phi37411 & GLS & Yes & Yes & No & & \\
\hline $3 d$ & phi102228 & 2 & 2 & GLS & No & No & No \\
\hline $5 a$ & phi087 & 6 & 6 & GLS & No & No & No \\
\hline $5 b$ & phi109188 & 2 & 1 & GLS & Yes & No & No \\
\hline $5 c$ & $\mathrm{nc} 130$ & 5 & 3 & GLS & Yes & Yes & No \\
\hline $5 d$ & phi331888 & 2 & 2 & GLS & No & No & No \\
\hline $7 a$ & phi034 & 7 & 9 & ASI & Yes & Yes & No \\
\hline $7 \mathrm{~b}$ & phi1545 & 8 & 9 & ASI & Yes & No & Yes \\
\hline $7 c$ & phi114 & 11 & 15 & ASI & Yes & Yes & Yes \\
\hline $7 d$ & phi328175 & 2 & 2 & ASI & No & No & No \\
\hline $8 a$ & phi014 & 4 & 4 & TLB & Yes & No & No \\
\hline $8 b$ & phi233376 & 10 & 10 & TLB & No & No & No \\
\hline $8 c$ & umc1304 & 6 & 6 & TLB & No & No & No \\
\hline $8 d$ & umc1161 & 3 & 1 & TLB & Yes & No & No \\
\hline $9 a$ & umc1279 & 3 & 2 & $\mathrm{GN}$ & Yes & No & No \\
\hline $9 b$ & umc127 & 7 & 4 & GN & Yes & No & No \\
\hline $9 c$ & phi032 & 5 & 5 & GN & No & No & No \\
\hline $9 d$ & phi44888 & 7 & 7 & $\mathrm{GN}$ & No & No & No \\
\hline
\end{tabular}

MSV = maize streak virus; GLS = grey leaf spot; $G N=$ grain number; $T L B=$ turcicum leaf blight; $A S I$ = anthesis to silking interval

3.85). Other loci were, however, inconsistent being useful in the polymorphism screen, but not in the backcross generations.

Zein proteins as tools for background selection of $\mathbf{0 2}$ modifiers. The zein fractions of seed proteins were more abundant at 18 days after pollination (DAP) than at 6 DAP (Fig. 4). There was enhanced levels of the 27-kDa $\gamma$ zein proteins in kernels with acceptable modification levels of 2 and 3. The levels of the 22-KDa $\alpha$ and the $19-\mathrm{kDa}$ zein proteins was reduced in kernels of modification leves of 2 and 3 (Fig. 4).

Analysis at 6 and 18 DAP for the parents showed a clear difference between QPM and non-QPM material. Within the 15 to $20 \mathrm{kDa}$ region, more proteins were partitioned to the zein fraction at 18 DAP in CML176 and 136R, than at $6 \mathrm{DAP}$ as expected. This is shown by the thick, intense bands at 18 DAP than at 6 DAP.

\section{Phenotypic traits for background selection}

Resistance to endemic diseases. Significant differences $(\mathrm{P}<0.05)$ were observed between parents and their backcross progeny for reaction to maize streak virus disease $(\mathrm{P}<0.05)$ (Table 3 ). The mean severity score for MSVD ranged from 1.53 to 2.40 in the recurrent parents $136 \mathrm{R}$ and $\mathrm{BC}_{2} \mathrm{~F}_{2}$ progeny, respectively. The highest severity for GLS was observed in the parents both having a mean score of 2.03 (Table 3). No significant differences $(\mathrm{P}>0.05)$ were observed between the recurrent parents and their advanced progeny (Table 3). Whereas non-significant 


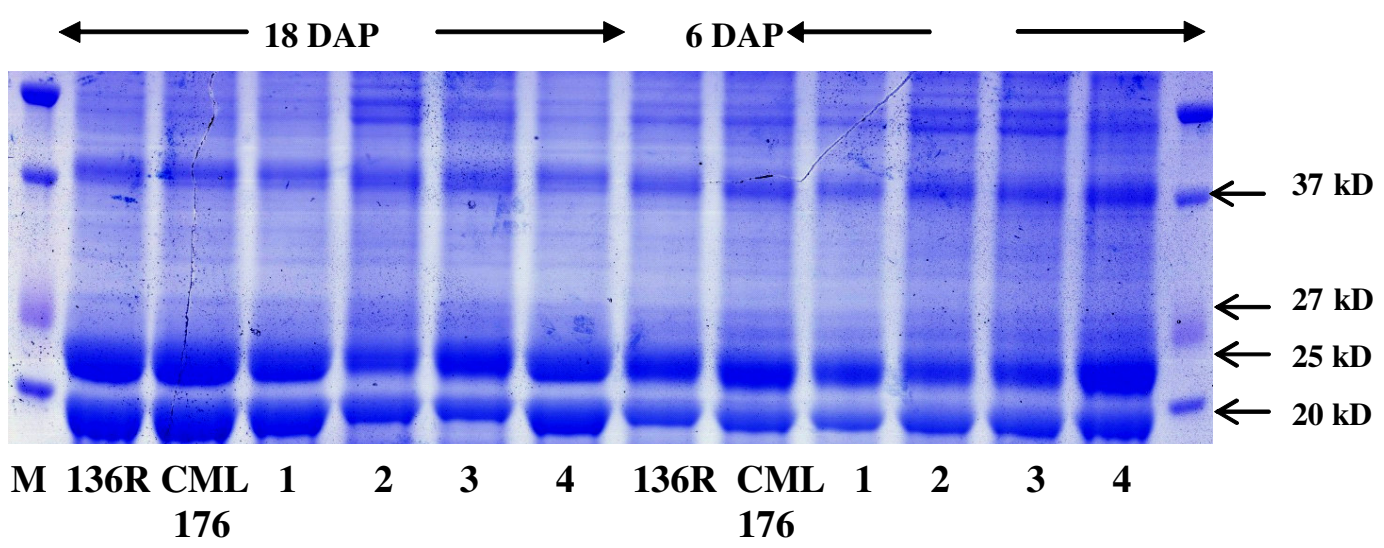

Figure 4. Zein accumulation in normal (136R), QPM (CML 176) and QPM of varying levels of modification 1-4 taken from total zein proteins extracted and assayed using SDS-PAGE at 18 and 6 days after pollination (DAP).

TABLE 3. Disease reactions of parents and their backcross progeny assessed for recovery of the recurrent parent genome $(136 R)$

\begin{tabular}{|c|c|c|c|}
\hline \multirow[t]{2}{*}{ Population } & \multicolumn{3}{|c|}{ Phenotypic attribute } \\
\hline & Maize streak gemini virus disease & ${ }^{\mathrm{a} G r e y ~ l e a f ~ s p o t ~}$ & ${ }^{\mathrm{b}}$ Turcicum leaf blight \\
\hline \multicolumn{4}{|l|}{ Parent } \\
\hline${ }^{\circ} \mathrm{CML} 176$ & 2.13 & 2.03 & 2.10 \\
\hline d136R & 1.53 & 2.03 & 2.35 \\
\hline \multicolumn{4}{|l|}{ Progeny } \\
\hline $\mathrm{BC}_{1} \mathrm{~F}_{1}$ & 1.97 & 1.73 & 2.13 \\
\hline $\mathrm{BC} \mathrm{F}_{2}$ & 2.40 & 1.90 & 1.90 \\
\hline LSD $_{0.05}$ & 0.46 & NS & NS \\
\hline CV $(\%)$ & 14.00 & 19.60 & 15.00 \\
\hline
\end{tabular}

Disease reaction (for MSVD, GLS, and TLB) were rated using a qualitative scale of $1-5$. Where $1=$ resistant and $5=$ susceptible based on the chlorotic/streaked areas on the leaf surface (Kyetere et al., 1999; Muriithi and Mutinda, 2001). a = Grey leaf spot is caused by Cercospora zeae-maydis (Tehon and Daniels), $b=$ Turcicum leaf blight is caused by Exserohilum turicum Pass teliomorph Setosphaeria turcica, Leonard and Suggs. $C=$ Parent is a CIMMYT maize Line and $d=$ Recycled line produced by the National Cereals Programme of the National Agricultural Research Institute NARO. BC = Backcross populations

$(P>0.05)$ differences were observed between recurrent and non-recurrent parent, the nonrecurrent QPM donor parent CML 176 had relatively lower disease severity than the recurrent parent 136R. The differences were based on assessment of disease severity (Table 4). In general, the reaction of the backcross progeny was comparable to CML 176 and 136R.

Phenotypic traits. Significant differences $(\mathrm{P}<0.05)$ were observed with respect to plant and ear heights especially for CML 176 the QPM donor. CML 176 was $20 \%$ taller than the non-recurrent parents $136 \mathrm{R}$, at $128.21 \mathrm{~cm}$ for BC1F2 and $128.19 \mathrm{~cm}$ for BC2F2. Similarly, ear height was greatest for CML $176(53.73 \mathrm{~cm})$ but not greater than that of BC1F2 progen. The recurrent parent $136 \mathrm{R}$ at $43.6 \mathrm{~cm}$ was the shortest genotype (Table 4). Ear heights of backcross progeny in general were not significantly different $(\mathrm{P}>0.05)$ from their recurrent parent $136 \mathrm{R}$, although, both were 
TABLE 4. Means of phenotypic traits used for background selection

\begin{tabular}{|c|c|c|c|c|}
\hline \multirow[t]{2}{*}{ Population } & \multicolumn{4}{|c|}{ Phenotypic attribute } \\
\hline & aPlant height $(\mathrm{cm})$ & ${ }^{\mathrm{a} E a r}$ height $(\mathrm{cm})$ & a1000 grain weight $(\mathrm{g})$ & aAnthesis-to-silking interval \\
\hline \multicolumn{5}{|l|}{ Parent } \\
\hline${ }^{\mathrm{b}} \mathrm{CML} 176$ & 155.57 & 53.73 & 263.20 & 2.00 \\
\hline c136R & 129.31 & 43.46 & 290.80 & 1.60 \\
\hline \multicolumn{5}{|l|}{ Progeny } \\
\hline $\mathrm{BC} \mathrm{F}_{1}$ & 129.12 & 52.22 & 273.90 & 2.35 \\
\hline $\mathrm{BC} 1 \mathrm{~F}_{2}$ & 128.19 & 58.25 & 289.90 & 2.10 \\
\hline LSD $_{0.05}$ & 4.80 & 3.40 & NS & NS \\
\hline CV $(\%)$ & 2.20 & 4.10 & 17.20 & 27.00 \\
\hline
\end{tabular}

$\mathrm{a}=$ Plant height was recorded in $\mathrm{cm}, 1000$ grain weight (at $12 \%$ moisture content), ear height in $\mathrm{cm}$, anthesis was based on days to silking and days to pollen shed (Babu et al., 2004a). $\quad b=$ Parent is a CIMMYT maize Line and $c=$ Recycled line produced by the National Cereals Programme of the National Agricultural Research Institute NARO. BC = Backcross populations

significantly higher than 136R. Grain weight and anthesis-to-silking interval were not significantly different $(\mathrm{P}>0.05)$ between the parents and the progeny with the progeny scoring mid- parent values in both backcross progeny. The recurrent parent 136R had similar properties to backcross with respect to pollen shed, but were different from the non-recurrent parent CML 176 (Table 4).

\section{DISCUSSION}

Molecular markers for background selection of critical agronomic traits. Traits regulated by earlier mapped QTL such as the MSVD resistance locus (Kyetere et al., 1999), were suitable for background selection of the recurrent parent genome (Table 2). Plant and ear/ cob height were also suitable as background selection traits (Table 3 ) that could be used to assay for recovery of the recurrent parent genome. Other critical traits such as resistance to turcicum leaf blight, grey leaf spot disease, yield were not consistent when progeny and their recurrent parents were compared. One explanation could be that these traits are controlled by multiple loci mapped at different parts of the genome, and are critically affected by genotype by environment interactions (Monna et al., 2002; Babu et al., 2004b).
Moreover, any backcross progeny will deviate from the expected phenotypes due to recombination and/or linkage between the target genes from the donor parents and nearby genes (Ribaut and Hoisington, 1998). Such linkage drag could be minimised through line conversion, albeit, breeders do not have any direct control over the size or recombination break points (Semagn et al., 2006).

A screen of potential SSR markers linked to agronomic traits of importance or located on chromosome 7 (the chromosome containing loci that modulate 02 modification) revealed high variability exhibited as dominant and codominant phenotypes (Fig. 2). The average number of alleles was 4.15 for the 24 SSR loci assayed and was relatively higher than those previously reported in maize inbreds. For instance, Bante and Prasanna (2003) reported 3.25 alleles using 36 SSR loci, while Warburton et al. (2002) observed 4.9 alleles from 88 SSR loci. Variability in the nature and number of SSR alleles has been attributed to factors such as number of SSR loci and repeat types; and methodologies used for detection of polymorphic markers as well as mutations at specific loci (Liu et al., 2003; Legesse et al., 2007).

In this study, only five of 24 SSR loci associated with traits of agronomic importance 
could be consistently used for background selection. These traits map to loci on chromosomes $3,5,7$, respectively. The SSR loci are associated with quantitative trait loci (QTL) conditioning resistance in maize to GLS (on chromosome 3 and 5) and anthesis-to-silking interval (ASI) (on chromosome 7). These loci affect important agronomic traits such as disease resistance and maturity rate, that in advertently influences adaptability to drought and yield of the crop (Babu-Rivandra et al., 2005; Pratt and Gordon, 2006).

A comparison of usable SSR loci for background selection shows that only in the case of disease resistance were putative SSR found, in this case for GLS (Fig. 3). Recent studies on potential use of candidate SSR linked to QTL, associated with resistance to multiple foliar pathogens of maize identified consensus QTL whose presence in germplasm increased resistance (Asea et al., 2009). In the case of GLS, the consensus QTL were on bins 4.08, 5.04 for TLB and 1.04 for MSVD (Asea et al., 2009). The consistent identification of SSR associated with GLS mapped QTL, thus demonstrates, the potential usefulness of this locus for background selection. Recent reviews on QTL estimation reveal that different mapping populations generally share only small sets of common QTL.

In complex genomes, the rate of unexpected results increase when moving from QTL to genes and when dealing with complex traits (Stuber, 1995). Thus, very few QTL/marker associations are valid in a genetically broad breeding programmes (Semagn et al., 2006). Moreover, the failure to identify consistently usable putative SSR tagged to traits of agronomic importance is not unique to this study and emphasises the need for fine-mapping, saturation of loci with more markers and QTL validation, prior to undertaking marker-based selection (Geiger and Welz, 2000; Semagn et al., 2006; Asea et al., 2009). The accuracy of molecular markers as tools for breeding complex traits is expected to improve with the completion of many crop genome sequencing projects especially rice, maize, sorghum, lucern etc. Overall, these results emphasize the need for combined use of both phenotypic and molecular marker data as appropriate, especially when selecting for complex traits.

Given that the recurrent parent genome in advanced backcross generations will have a relatively higher proportion of desirable genome, in spite of linkage drag, the combined use of reproducible and well characterised simply inherited traits could help speed up selection processes. Using this approach for example, one can clearly identify promising lines without going through the rigour of artificial inoculation with pathogens early in the crop growth cycle.

Zein proteins as tools for background selection of 02 modifiers. During the early stages of seed development (6 - 18 DAP), there is increased accumulation of protein bodies as well as increased expression of starch biosynthesis genes needed for extension and packing of starch granules in developing endosperm. This study also showed relatively elevated levels of the $27-\mathrm{kDa} \gamma$ zein proteins in kernels with acceptable modification levels of 2 and 3, respectively and reduced levels of the $22 \mathrm{kDA}$ and $19 \mathrm{kDa}$ zein in kernels of modification levels 2 and 3. Clearly, the zeins can be used as tools for selecting good modifier background in QPM maize breeding. Of the three assayed zein proteins in this study, the best candidate is the $27-\mathrm{kDa} \gamma$ zein whose increased level of expression leads to high lysine content in developing endorsperm (Geether et al., 1991; Gibbon et al., 2003). Assays could also be done at $18 \mathrm{DAP}$ when both starch syntheses and zein protein gene expression is at maximum (Woo et al., 2001; Hunter et al., 2002).

The use of the $27 \mathrm{kDa} \gamma$-zein proteins may, however, be compounded by low detection, given that it makes up 5 to $10 \%$ of the total zein compared to 75 to $80 \%$ of the 20 to $24 \mathrm{kDa}$ proteins (Esen, 1985). The use of the $27 \mathrm{kDa}$ zein protein fraction should not therefore be done in isolation. In this study, we used both 22 and $19 \mathrm{kDa}$ zein fractions and demonstrated that their low levels were correlated well with level 2 and 3 modification levels (Fig. 4) usually selected as good quality QPM. Cheap protein assays such as the SDS /PAGE could be done 
targeting the low molecular weight fraction early in the crop's life. These assays could be done as early as 18 DAP to increase the opportunity for early selection of promising lines, and could be coupled with assays of non-zein genes known to be involved in modification, such as starch synthases and protein synthesis elongation factor (EF-1a) (Moro et al., 1996; Gibbon et al., 2003; Gibbon and Larkins, 2005, Wu et al., 2010).

Phenotypic descriptors as tools for background selection of the recurrent parent genome. Stable expression of these phenotypic traits in backcross families shows that they can be used to estimate recovery of the recurrent parent genome. Whereas backcross breeding is essentially well suited for handling monogenic traits, it has also been used to transfer quantitative traits with moderate to high heritability (Pratt and Gordon, 2006). In maize, moderate to high heritability for turcicum leaf blight, grey leaf spot and maize streak virus disease, respectively have been reported (Asea et al., 2009). Therefore, in the context of this work, the stability of these traits, perhaps due to the high heritability, confirms their suitability as selection tools for recurrent parent genome recovery.

The success of a backcross breeding scheme for quantitative traits is limited by the ability to select for suitable intensity of the target trait. From literature, GLS and TLB are conditioned by quantitative and a combination of quantitative and qualitative genes, respectively (Asea et al., 2009). Quantitative resistance to TLB is generally expressed as smaller and fewer nectrotic lesions, while qualitative resistance is condition by $\mathrm{Ht}$ genes characterised by chrolotic type of lesions (Pratt, 2004). In this study, no chlorotic lesions were observed indicative of quantitative.

Resistance to MSVD is qualitative (Kyetere et al., 1999). Moreover, resistance loci to all these diseases spans different parts of the maize genome and with loci being diffuse over the ten chromosomes of maize and in some cases on the same chromosome (Wisser, 2006). Thus, selecting for these traits simultaneously provides a suitable mechanism to estimate recurrent parent genome recovery during breeding. Similar observations have been made for rice blast in which segments of recurrent parent genome including previous breeding history was found in BC5 populations (Jia, 2009).

\section{CONCLUSION}

The 27-kDa $\gamma$ zein protein was suitable for background selection for kernel modification compared to other zeins proteins. It should, however, be used along with the $22 \mathrm{kDA}$ and 19 kDa zein proteins, SSR markers mapped to chromosomes 3, 5, 7 associated with QTL conditioning resistance in maize to GLS and anthesis to silking interval were suitable for background selection. Simply inherited plant phenotypes such as MSVD resistance are useful as complementary phenotypic selection systems.

\section{ACKNOWLEDGEMENT}

This work was financed by Regional Universities Forum for Capacity Building in Agriculture (RUFORUM), (Grant number RUCG012) and the East African Regional Programme and Research Network (BIO-EARN) (Project Number 1).

\section{REFERENCES}

Asea, G., Vivek, B. S., Bigirwa, G., Lipps, P. E. and Pratt, R. C. 2009. Validation of consensus quantitative trait loci associated with resistance to multiple foliar pathogens of maize. Phytopathology 99:540-547.

Babu Rivandra E., Sudha, K., Nair, B., Prasanna, B.M and Gupta, H.S. 2004a. Integrating marker assisted selection in crop breeding Prospects and Challenges. Current Science 87: 607-619.

Babu Rivandra, E., Mani, V.P and Gupta, H.S. 2004b. Combining high protein quality and hard endosperm traits through phenotypic and marker assisted selection in maize. The Regional Institute. URL http://www. cropscience.org.au Accessed on 9 September, 2010. 
Babu Rivandra, E., Nair, S.K., Kumar, A., Venkatesh, S.M., Sekhar, J.C., Singh, N.N., Srinivasan, G and Gupta, H.S. 2005. Two generation marker-aided backcrossing for rapid conversion of normal maize lines to quality protein maize. Theoretical Applied Genetics 111: 888-897.

Bantte, K. and Prasanna, B.M. 2003. Simple sequence repeat polymorphism in quality protein maize (QPM) lines. Euphytica 129: 337-344.

Bantte, K. and Prasanna, B.M. 2004. Endosperm protein quality and kernel modification in the quality protein maize inbred lines. Journal of Plant Biochemistry and Biotechnology 13: 57-60.

Centro Internacional de Mejoramiento de Maíz y Trigo (CIMMYT). 2005. Quality protein maize: Targets poorest in Africa. URL http:/ /www. cimmyt.org Accessed 9 September, 2010.

Coleman, C.E., Clore, A.M., Ranch, .J.P., Higgins, R., Lopes, M.A. and Larkins, B.A. 1997. Expression of a mutant $\alpha$-zein creates the floury-2 phenotype in transgenic maize. Proceedings of the National Academy of Sciences of the United States 94:70947097.

Denic, M., Chaque, P., Fato, P., Senete, C, Mariote, D. and Haag, W. 2008. Approaches in breeding for high quality protein maize. Genetika 40: 237-247.

Esen, A. 1985. Separation of alcohol soluble proteins (zeins) from maize into three fractions by differential solubility. Plant Physiology 80: 623-627.

Frisch, M., Bohn, M. and Melchinger, A.E. 1999. Comparison for selected marker assisted backcrossing of a gene. Crop Breeding 39: 1295-1301.

Geiger, H.H. and Welz, H.Z. 2000. Principles of marker assisted selection: Quantitative Traits In: Application of molecular markers in plant breeding. Training manual for a seminar held at IITA. Haussman, B.I.G, Geiger, H.H., Hess, D.E., Hash, C.T. and Bramel-Cox, P. (Eds.), Ibadan , Nigeria 1617 August 1999.

Geetha, K.B. Lending, C.R., Lopes, M.A., Wallace, J.C. and Larkins, B.A. 1991.
Opaque-2 modifiers increase gamma-zein synthesis and alter its spatial-distribution in maize endosperm. Plant Cell 3:1207-1219.

Gibbon, B.C., Wang, X. and Larkins, B.A. 2003. Altered starch structure is associated with endosperm modification in Quality Protein Maize. Proceedings of the National of the United States Academy of Sciences 100: 15329- 15334.

Gibbon, B.C. and Larkins, B.A. 2005. Molecular genetic approaches to developing quality protein maize. Trends in Genetics 21: 227233.

Gupta, H. S., Agrawal, P. K., Mahajan, V., Bisht, G. S., Kumar, A., Verma, P., Srivastava, A., Saha, S., Babu, R., Pant, M. C. and Mani, V. P. 2009. Quality protein maize for nutritional security: rapid development of short duration hybrids through molecular marker assisted breeding. Current Science 96:231237.

Hoisington, D., Khairallah, M. and Gonzalez-deLeon, D. 1994. Laboratory protocols: CIMMYT Applied Molecular Genetics Laboratory. 2nd ed.CIMMYT. Mexico.

Hoisington, D. 2002. Opportunities for nutritionally enhanced maize and wheat varieties to combat protein and micronutrient malnutrition. In: Biotechnolgy-derived Nutritious Foods for developing. Bouis, H.E., Lineback, D. and Schneeman, B. (Eds.). Countries: Needs, Opportunities and Barriers. Food and Nutrition Bulletin 23(4):376- 378.

Hunter, B.G., Beatty, M.K., Singletary, G.W., Hamaker, B.R., Dilkes, B.P., Larkins, B.A. and Jung, R. 2002. Maize opaque endosperm mutations create extensive changes in patterns of gene expression. The Plant Cell 14: 2591-2612.

Jia, Y., Correa-Victoria, F., McClung, A., Zhu, L., Liu, G., Wamishe, Y., Xie, J., Marchetti, M. A., Pinson, S. R. M., Rutger, J. N. and Correll, J. C. 2007. Rapid determination of rice cultivar responses to the sheath blight pathogen Rhizoctonia solani using a microchamber screening method. Plant Disease 91:485-489.

Krivanek, A.F., Groote, H.D., Gunaratna, N.S., Diallo, A.O. and Friesen, D. 2007. Breeding 
and disseminating quality protein maize (QPM) for Africa. African Journal of Biotechnology 6:312-324.

Kyetere, D.T., Ming, R., McMullen, M.D., Pratt, R.C., Brewbaker, J. and Musket, T. 1999. Genetic analysis of tolerance to maize streak virus in maize. Genome 42:20-26.

Legesse, B.W., Myburg, A.A., Pixley, K.V. and Botha, A.M. 2007. Genetic diversity of African inbred lines revealed by SSR markers. Hereditas 144: 10-17

Lehmesiek, A., Esterhuizen, A. M., Van Staden, D., Nelson, S.W. and Retiel, A.E. 2001. Genetic mapping of grey leaf spot resistance genes in maize. Theoretical Applied Genetics 3 :797-803.

Liu, K., Goodman, M. and Muse, S. 2003. Genetic structure and diversity among maize inbred lines as inferred from DNA microsatellites. Genetics 165: 2117-2128.

Lopes, M.A. and Larkins, B.A. 1991. Gammazein content is related to endosperm modiûcation in Quality Protein Maize. Crop Science 31:1655-1662.

Lopes, M.A., Takasaki, K., Bostwick, D.E., Helentjaris, T. and Larkins, B.A. 1995. Identification of two opaque 2 modifier loci in quality protein maize. Molecular and General Genetics 247: 603-613.

Manna, R., Okello, D. K., Imanywoha, J., Pixley, $\mathrm{K}$ and Edema, R. 2006. Enhancing Introgression of the opaque- 2 trait into maize lines using simple sequence repeats. African Crop Science Journal 13: 215-226.

Mertz, E.T., Bates, L.S. and Nelson, O.E. 1964. Mutant gene that changes the protein composition and increases the lysine content of maize endosperm. Science 145: 279-280.

Monna, L., Lin, H.X., Kojima, S. and Sasaki, T. 2002. Genetic dissection of genomic region for a quantitative trait locus, $\mathrm{Hd} 3$, into two loci, $\mathrm{Hd} 3 \mathrm{a}$ and $\mathrm{Hd} 3 \mathrm{~b}$, controlling heading datein rice. Theoretical Applied Genetics 104: 772-778.

Moose, S.P., Dudley, J.W. and Rocheford, T.R. 2004. Maize selection passes the century mark: A unique resource for $21^{\text {st }}$ century genomics. Trends in Plant Science 9: 358364. 23.
Moro, G.L., Habben, J.E., Mamaker, B.R. and Larkins, B.A. 1996. Characterisation of the variability in lysine content for normal and opaque maize endosperm. Crop Science36: 1651-1659.

Muriithi, L.M. and Mutinda, C.J. 2001. Genetic variability of maize genotypes for resistance to Exerohilum turcicum in Kenya. Seventh Eastern and Southern Africa Regional Maize Conference 11-15 ${ }^{\text {th }}$ February. pp. 106-109.

Ngaboyisonga, C., Njoroge, K., Kirubi, D. and Githiri, S.M. 2006. Effects of low nitrogen and drought on grain yield and endosperm hardness of quality protein maize single cross hybrids. In: International Plant Breeding Symposium, Mexico City. Mexico. pp. 137.

Okello, D. K., Manna, R., Imanywoha, J., Pixley, K. and Edema, R. 2006. Agronomic performance of selected inbred lines for improvement of protein quality of adapted Ugandan maize germplasm. African Crop Science Journal 14: 37-47.

Okori, P., Bigirwa, G., Asea, G. and Adipala, E. 1999. An overview of the status of maize disease in Uganda. African Crop Science Conference Proceedings 4: 463-468.

Pixley, K.V. 2001. QPM in southern Africa. CIMMYT, Zimbabwe.

Pratt, R.C. 2004. Molecular marker assisted selection (MAS) procedures for improvement of quality protein maize (QPM) germplasm. Latin America and Caribbean meeting on agricultural biotechnology. Boca Chica, Dominican Republic June 21-25.

Pratt, R. C. and Gordon, S. G. 2006. Breeding for resistance to maize foliar pathogens. Plant Breeding Reviews 26:119-173.

Ribaut, J.M. and Hoisington, D. 1998. Marker Assisted Selection Tools and Strategies. Trends in Plant Sciences 3:236-239.

Schmidt, R.J 1993. Opaque-2 and zein gene expression. In: Control of plant gene expression. Verma, D.P.S. (Ed.), pp. 337355. CRC Press, Inc.

Semagn, K., Bjørnstad, A. and Ndjiondjop, M.N. 2006. Progress and prospects of marker assisted backcrossing as a tool in crop 
breeding programmes. African Journal of Biotechnology 5:2588-2603.

Steel, R.G.D., Torrie, J.H. and Dickey, D.A. 1997. Principles and procedures of statistics. A biometrical approach. $3^{\text {rd }} \mathrm{Ed}$. The McGraw-Hill Company, New York. USA.

Stratagene 1998. CastAway ${ }^{\mathrm{TM}}$ Silver staining protocol for sequencing gels. Stratagene products Manual. California, USA.

Stuber, C.W. 1995. Mapping and manipulating quantitative traits in maize. Trends in Genetics 11: 477-81.

Warburton, M. L., Xianchun, X. and Crossa, J. 2002. Genetic characterization of CIMMYT inbred maize lines and open pollinated populations using large scale fingerprinting methods. Crop Science 42: 1832-1840.

Woo, Y.M., Hu, D.W., Larkins, B.A. and Jung, R. 2001. Genomic analysis of genes expressed in maize endosperm identifies novel seed proteins and clarifies patterns of zein gene expression. Plant Cell 13: 2297-2317.
Xiao, Y.N., Li, X.N., George, M.L., Li, M.S., Zhang, S.H. and Zheng, Y.L. 2005. Quantitative trait locus analysis of drought tolerance and yield in maize in China. Plant Molecular Biology Reporter 23: 155-165.

Wang, X.L. White, P. Pollak, L. and Jane, J. L. 2001. Quantitative trait locus mapping of loci influencing elongation factor 1 alpha content in maize endosperm. Plant Physiology 125: 1271-1282.

Wisser, R. J., Balint-Kurti, P. J. and Nelson, R. J. 2006. The genetic architecture of disease resistance in maize: A synthesis of published studies. Phytopathology 96:120-129.

Wu, Y., Holding, D.R. and Messing, J. 2010. $\alpha$ Zeins are essential for endosperm modification in quality protein maize. Proceedings of the National Academy of Sciences of the United States 107:1281012815 